\title{
Unlearning: NMDA Receptor-Mediated Metaplasticity in the Anterior Piriform Cortex Following Early Odor Preference Training in Rats
}

\author{
Bandhan Mukherjee, ${ }^{1}$ Gillian L. Morrison, ${ }^{1}$ Christine J. Fontaine, ${ }^{1,3}$ Qinlong Hou, ${ }^{1}$ Carolyn W. Harley, ${ }^{2}$ and Qi Yuan ${ }^{1}$ \\ ${ }^{1}$ Division of Biomedical Sciences, Faculty of Medicine and 'Department of Psychology, Faculty of Science, Memorial University of Newfoundland, St. John's, \\ Newfoundland A1B 3V6, Canada, and ${ }^{3}$ Neuroscience Program, Victoria University, Victoria, British Columbia V8P 5C2, Canada
}

Here we demonstrate metaplastic effect of a change in NMDA receptor (NMDAR) number in the anterior piriform cortex (aPC) in rat induced by a $10 \mathrm{~min}$ pairing of peppermint odor + stroking, which significantly modifies later learning and memory. Using isolated synaptoneurosomes, we found NR1 receptor downregulation $3 \mathrm{~h}$ after training and upregulation at $24 \mathrm{~h}$. Consistent with the NR1 pattern, the NMDAR-mediated EPSP was smaller at $3 \mathrm{~h}$ and larger at $24 \mathrm{~h}$. Subunit composition was unchanged. Whereas LTP was reduced at both times by training, LTD was facilitated only at $3 \mathrm{~h}$. Behaviorally, pups, given a pairing of peppermint + stroking $3 \mathrm{~h}$ after an initial peppermint + stroking training, lost the normally acquired peppermint preference $24 \mathrm{~h}$ later. To probe the pathway specificity of this unlearning effect, pups were trained first with peppermint and then, at $3 \mathrm{~h}$, given a second training with peppermint or vanillin. Pups given peppermint training at both times lost the learned peppermint preference. Pups given vanillin retraining at $3 \mathrm{~h} \mathrm{had} \mathrm{normal}$ peppermint preference. Downregulating NR1 with siRNA prevented odor preference learning. Finally, the NMDAR antagonist MK-801 blocked the LTD facilitation seen $3 \mathrm{~h}$ after training, and giving MK-801 before the second peppermint training trial eliminated the loss of peppermint odor preference. A training-associated reduction in NMDARs facilitates LTD $3 \mathrm{~h}$ later; training at the time of LTD facilitation reverses an LTP-dependent odor preference. Experience-dependent, pathway-specific metaplastic effects in a cortical structure have broad implications for the optimal spacing of learning experiences.

Key words: LTD; LTP; NMDAR; olfactory learning; piriform cortex; rat

\section{Introduction}

Early odor preference learning in the week old rat pup is a wellstudied model of Pavlovian associative conditioning (Wilson and Sullivan, 1994). As rat pups have neither normal visual nor auditory input, they are dependent for survival on the dam; thus, orienting to dam-associated odors is essential (Gregory and Pfaff, 1971). Odor associative learning also occurs in newborn human infants (Varendi et al., 1996; Sullivan and Toubas, 1998). In the rat pup model, a single 10 min pairing of odor (conditioned stimulus) and maternal care signals, such as dorsal whole-body stroking (unconditioned stimulus), induces a protein synthesisdependent $24 \mathrm{~h}$ odor preference memory (Grimes et al., 2011).

In addition to neural changes in the olfactory bulb, which have been extensively studied (Sullivan and Wilson, 2003; Yuan et al., 2003), neural changes in the anterior piriform cortex (aPC) are

\footnotetext{
Received Jan. 11, 2014; revised Feb. 25, 2014; accepted March 3, 2014.

Author contributions: Q.Y. designed research; B.M., G.L.M., C.J.F., Q.H., and Q.Y. performed research; B.M., G.L.M., C.J.F., Q.H., and Q.Y. analyzed data; B.M., C.W.H., and Q.Y. wrote the paper.

This work was supported by Canadian Institutes of Health Research Operating Grant MOP-102624 to Q.Y.

The authors declare no competing financial interests.

Correspondence should be addressed to Dr. Qi Yuan, Division of Biomedical Sciences, Faculty of Medicine, Memorial University, 300 Prince Philip Drive, St. John's, Newfoundland A1B 3V6, Canada. E-mail: qi.yuan@med.mun.ca.

D0I:10.1523/JNEUROSCI.0128-14.2014

Copyright $\odot 2014$ the authors $\quad 0270-6474 / 14 / 345143-09 \$ 15.00 / 0$
}

also necessary, and sufficient, for the expression of early odor preference learning (Morrison et al., 2013). A conditioned stimulus, typically peppermint odor, paired with a $\beta$-adrenoceptor agonist infusion in aPC, induces odor preference learning, whereas either a locally infused $\beta$-adrenoceptor antagonist or a locally infused NMDA receptor (NMDAR) antagonist prevents odor preference learning.

A strong feature of the rat pup odor-conditioning model is that the anterior commissure is not yet developed (Kucharski and Hall, 1987) and odor input can be restricted to a single hemisphere using temporary unilateral naris occlusion during training (Yuan and Harley, 2012; Fontaine et al., 2013). The reduction in response variability permitted by this within-subject control revealed, in ex vivo slices, that an increase in the AMPA receptor (AMPAR)-mediated synaptic response to lateral olfactory tract (LOT) input in the aPC parallels odor preference memory (Fontaine et al., 2013; Morrison et al., 2013). Calcium imaging in the same preparation reveals an increase in the activation of pyramidal cells in aPC after training (Fontaine et al., 2013), implying a stronger network representation for the trained odor.

The NMDAR plays a critical role as a coincidence detector for mediating AMPAR plasticity in associative learning (Malenka and Bear, 2004), including early odor preference learning (Lethbridge et al., 2012; Morrison et al., 2013). Research in the past two decades has provided evidence that the NMDAR itself is dynamic 
and undergoes plastic changes, including changes in the number of receptors and in subunit composition (Bellone and Nicoll, 2007). Long-term plasticity of NMDAR-mediated synaptic transmission, such as long-term potentiation (LTP) and long-term depression (LTD), has been extensively characterized in vitro, using acute brain slices and neuronal cultures (Abraham and Bear, 1996; Hunt and Castillo, 2012). Activity-dependent NMDAR plasticity in vivo has been reported in the visual cortex (Carmignoto and Vicini, 1992; Philpot et al., 2001) and the olfactory system (Quinlan et al., 2004; Franks and Isaacson, 2005; Lethbridge et al., 2012). However, its functional significance in learning is not well understood. Here, we examine odor traininginduced modulation of the NMDAR and its associated plasticity effects in the aPC. We find metaplastic, pathway-specific changes that modulate the rat pup response to subsequent associative odor training.

\section{Materials and Methods}

Animals and ethics statement

All experimental procedures were approved by the Institutional Animal Care Committee at Memorial University of Newfoundland with adherence to the guidelines set by the Canadian Council on Animal Care. Sprague Dawley rat pups of either sex (Charles River) were used in this study. Animals were bred, and pups were born on-site at the research facility. Litters were culled to 12 pups with equal numbers of males and females on postnatal day 1 (PD1; day of birth is designated PD0). Dams were maintained with ad libitum access to food and water.

\section{Behavioral studies}

Behavioral experiments were performed in a temperature-controlled room at $\sim 28^{\circ} \mathrm{C}$ and followed the standard protocol previously established for early odor preference learning (Sullivan and Leon, 1987; McLean et al., 1999) as described below. One-way ANOVAs and post hoc Fisher tests were used to determine statistical significance throughout the experiments.

\section{Odor preference training and testing}

On PD6 or PD7, pups were assigned to an odor plus stroking $\left(\mathrm{O} / \mathrm{S}^{+}\right)$or an odor only $\left(\mathrm{O} / \mathrm{S}^{-}\right)$condition. Pups were removed from the nest and placed on normal bedding for $10 \mathrm{~min}$. After this habituation period, pups receiving conditioning training $\left(\mathrm{O} / \mathrm{S}^{+}\right)$were placed on scented bedding (peppermint or vanillin; $0.3 \mathrm{ml}$ odorant extract in $500 \mathrm{ml}$ bedding) and vigorously stroked with a paintbrush for $30 \mathrm{~s}$, followed by a $30 \mathrm{~s}$ rest, for a total of $10 \mathrm{~min}$. Pups in the nonlearning condition $\left(\mathrm{O} / \mathrm{S}^{-}\right)$were placed in peppermint-scented bedding for $10 \mathrm{~min}$ without stroking, following the habituation period. Pups were returned to the dam after training.

For $\mathrm{O} / \mathrm{S}^{+}$pups that were retrained at 3 or $24 \mathrm{~h}$ after the first training, they were exposed to peppermint or vanillin-scented bedding while being stroked, with the same procedure as in the first training. A control group was initially trained with peppermint + stroking, and then retrained with peppermint odor only at $24 \mathrm{~h}$. A subset of peppermint + stroking retrained pups underwent systemic intraperitoneal injection of either MK-801, an NMDAR antagonist $(0.1 \mathrm{mg} / \mathrm{kg}$ in $50 \mu \mathrm{l}$ saline, Tocris Bioscience), or saline, $40 \mathrm{~min}$ before the onset of the retraining.

Twenty-four hours after a given training or retraining episode (e.g., $48 \mathrm{~h}$ after initial training for pups receiving a $24 \mathrm{~h}$ retraining event), pups were tested for odor preference memory using a two-choice odor preference procedure. The testing apparatus was a stainless steel box $(30 \times$ $20 \times 18 \mathrm{~cm}$ ) placed over two training boxes. One box contained peppermint-scented bedding, and the other contained normal, unscented bedding. Testing boxes were separated by a $2 \mathrm{~cm}$ neutral zone. For testing, pups were removed from the dam and placed in the neutral zone. Times that pups spent over scented versus normal bedding were recorded in five 1 minute trials, each separated by a 1 minute rest in a clean cage. The average time spent over peppermint bedding was calculated for each pup.

\section{Reversible naris occlusion for ex vivo experiments}

Nose plugs were constructed using polyethylene 20 (PE 20) tubing and silk surgical thread as per procedures described previously (Cummings et al., 1997; Morrison et al., 2013). A small dab of a sterile jelly of local anesthetic, 2\% xylocaine (Astra Zeneca), was applied to the left naris of the pup for $\sim 3 \mathrm{~min}$ before the plug was gently inserted in the left naris. The pup was then placed on unscented bedding to habituate to the nose plug, followed by appropriate odor conditioning training with peppermint-scented bedding. The nose plug was removed immediately after training, and pups returned to dams. Some control pups were subjected to naris occlusions only for the same amount of time without undergoing odor training. Pups that underwent lateralized odor training were killed at various time points for tissue collection for either Western blot or electrophysiological recording.

\section{Intracerebral infusion of siRNA}

siRNA for the NMDA NR1 receptor was infused into the aPC on PD3, followed by behavioral training on PD7. PD3 pups were anesthetized via hypothermia and placed in a stereotaxic apparatus in a skull flat position. A horizontal incision was made to expose the skull and two small holes were drilled. A total of $1 \mu \mathrm{l}$ of 1\% NR1 siRNA mixed in RNase-free vehicle (Dharmacon ACCELL siRNA delivery media, Thermo Scientific) or $1 \%$ control nontargeting siRNA was injected into the aPC ( $2 \mathrm{~mm}$ anterior to bregma, $3 \mathrm{~mm}$ bilateral, $5 \mathrm{~mm}$ below the surface) using a Hamilton syringe. In some pups, siRNA or control was injected into the olfactory bulbs. The injection was over $4 \mathrm{~min}$, and the syringe was left in site for another $6 \mathrm{~min}$ before being gently withdrawn from the brain. The skin was sutured and the pups recovered in a heated cage. Thirty minutes after recovery from the surgery, pups were returned to the dam.

On PD7, pups with bilateral NR1 siRNA or nontargeting control infusions underwent behavioral training and on the following day were tested with peppermint-scented bedding. Pups with unilateral NR1 siRNA infusion and nontargeting control siRNA injected into the opposite aPC or olfactory bulb were killed for tissue collection for Western blots.

\section{Western blots of synaptoneurosomes}

Three or $24 \mathrm{~h}$ after lateralized odor training, or on PD7 after unilateral NR1 siRNA injections (conducted on PD3), pups were decapitated, and aPCs or olfactory bulbs were collected and flash frozen on dry ice. Samples were stored at $-80^{\circ} \mathrm{C}$ until further processing.

\section{Synaptoneurosome isolation}

All samples were kept on ice during the synaptoneurosome extraction to minimize proteolysis. Brain samples were homogenized in oxygenated HEPES buffer (in mM: 50 HEPES, $124 \mathrm{NaCl}, 26 \mathrm{NaHCO}_{2}, 1.3 \mathrm{MgCl}_{2}, 2.5$ $\mathrm{CaCl}_{2}, 3.2 \mathrm{KCl}, 1.06 \mathrm{KH}_{2} \mathrm{PO}_{4}, 10$ glucose, 1 EDTA, $1 \mathrm{PMSF}$, complete protease inhibitor mixture (Roche), complete phosphatase inhibitor mixture (Roche), saturated with $95 \% \mathrm{O}_{2} / 5 \% \mathrm{CO}_{2}, \mathrm{pH} 7.4$, using Teflonglass tissue homogenizers (Thomas Scientific). Lysed samples were kept on ice for $10 \mathrm{~min}$ for incubation in the buffer and were then passed through 3 prewetted filters using a $13 \mathrm{~mm}$ diameter syringe filter holder (Millipore). The first two filters were $100 \mu \mathrm{m}$ nylon filters (Small Parts), and the last filter was a $5 \mu \mathrm{m}$ pore hydrophilic filter (Millipore). Filtrates were centrifuged at $1000 \times g$ for $20 \mathrm{~min}$ at $4^{\circ} \mathrm{C}$, after which the pellets were resuspended in HEPES buffer. These pellets represent the synaptoneurosome fraction. Protein concentrations for each sample were determined using a BCA protein assay kit (Pierce). The volume of lysate required to make $40 \mu \mathrm{g}$ of protein for each sample was calculated.

\section{Western blotting}

A total of $60 \mu$ l total volume solutions of lysate (volume required for 40 $\mu$ g protein), sample buffer $(0.3 \mathrm{~m}$ Tris- $\mathrm{HCl}, 10 \% \mathrm{SDS}, 50 \%$ glycerol, $0.25 \%$ bromophenol blue, $0.5 \mathrm{~m}$ dithiothreitol), and $\mathrm{d}_{2} \mathrm{O}$ were prepared and boiled for $5 \mathrm{~min}$ at $100^{\circ} \mathrm{C}$. Samples were then loaded into lanes of a 7.5\% SDS-PAGE gel, along with a protein ladder (Thermo Scientific) and loading buffer for empty lanes. Sample separation occurred through SDS-PAGE, followed by transference to a nitrocellulose membrane (GE Healthcare). Membranes were cut horizontally at the $72 \mathrm{kDa}$ level, and the upper portion was probed with a rabbit antibody for NR1 (1:2000, 
blocked in BSA; Cell Signaling Technology) subunits, and the lower portion was probed for $\beta$-actin (1:5000, blocked in 4\% skim milk; Cedarlane). Membranes were incubated in primary antibody and agitated overnight at $4^{\circ} \mathrm{C}$. Secondary antibodies bound to HRP were applied the following day (1:20,000, anti-rabbit; Pierce), and membranes were then washed in enhanced chemiluminescence Western blotting substrate (Pierce). Finally, blots were developed on x-ray film (AGFA).

Films were scanned onto a computer using an image scanner (CanoScan LiDE 200), and the optic density (OD) of each band was measured using ImageJ software. Each sample was normalized to the corresponding $\beta$-actin band that was run on the same gel. In pups that underwent lateralized odor training, each spared hemisphere was normalized to its naris-occluded counterpart. In pups with siRNA infusion, the NR1 siRNA-infused hemisphere was normalized to its nontargeting control counterpart. Experimental values are reported as mean \pm SEM of the relative expression of the normalized NR1 subunit. A one-way ANOVA was used to evaluate differences in the mean OD.

\section{Electrophysiology}

Tissue preparation and extracellular recording. Pups were anesthetized by halothane or isoflurane inhalation and quickly decapitated. Brain tissue was extracted and placed in a high glucose aCSF (in mM: $83 \mathrm{NaCl}, 2.5$ $\mathrm{KCl}, 0.5 \mathrm{CaCl}_{2}, 3.3 \mathrm{MgSO}_{4}, 1 \mathrm{NaH}_{2} \mathrm{PO}_{4}, 26.2 \mathrm{NaHCO}_{3}, 22$ glucose, and 72 sucrose, equilibrated with $95 \% \mathrm{O}_{2}$ and $5 \% \mathrm{CO}_{2}$ ) for $\sim 10 \mathrm{~min}$. Sagittal slices $(400 \mu \mathrm{m})$ of the piriform cortex were cut using a vibrating blade (Vibratome, 1000P, Leica Microsystems) and incubated at $34^{\circ} \mathrm{C}$ in the aforementioned solution for $30 \mathrm{~min}$ and then returned to room temperature. Tissue slices were recorded in aCSF (in mM: $119 \mathrm{NaCl}, 2.5 \mathrm{KCl}, 2.5$ $\mathrm{CaCl}_{2}, 1.3 \mathrm{MgSO}_{4}, 1 \mathrm{NaH}_{2} \mathrm{PO}_{4}, 26.2 \mathrm{NaHCO}_{3}, 22$ glucose, equilibrated with $95 \% \mathrm{O}_{2}$ and $5 \% \mathrm{CO}_{2}$ ) at $30^{\circ} \mathrm{C}-32^{\circ} \mathrm{C}$ and viewed with an upright microscope (Olympus; BX51). Extracellular field potentials were recorded with glass pipettes filled with aCSF and placed in layer Ia of the aPC. A concentric bipolar stimulating pipette (FHC) was lowered into the LOT and delivered single test pulses, ranging from 10 to $60 \mu \mathrm{A}$.

Electrophysiological data were recorded with Multiclamp 700B (Molecular Devices), filtered at $2 \mathrm{kHz}$, and digitized at $10 \mathrm{kHz}$. Data acquisition and analysis were performed with pClamp10 and ClampFit 2.10 (Molecular Devices) and Igor Pro 6.10A (WaveMetrics). Student's $t$ tests were used to determine statistical significance.

Ex vivo electrophysiology. PD7-PD10 pups undergoing ex vivo electrophysiological recording were subjected to odor conditioning with one naris occluded as described earlier. After a $10 \mathrm{~min}$ habituation period, pups underwent $\mathrm{O} / \mathrm{S}^{+}$or $\mathrm{O} / \mathrm{S}^{-}$training on peppermint-scented bedding. Upon completion, the plugs were removed and pups were returned to the dam. Pups were killed 3 or $24 \mathrm{~h}$ after training, and brain slices were prepared. The hemispheres of the brain were kept separately within the incubation chamber to achieve intra-animal control.

The NMDAR component of the field EPSP (fEPSP) was isolated using NBQX, an AMPAR antagonist ( $5 \mu \mathrm{M}$; Tocris Bioscience) and low $\mathrm{Mg}^{2+}$ $(100 \mu \mathrm{M})$ aCSF (Franks and Isaacson, 2005; Yuan and Harley, 2012). The NMDAR input/output (I/O) relationship was measured as the ratio of the slope of the fEPSP to the size of the presynaptic fiber volley and compared between the spared and occluded slices. The AMPAR component of the fEPSP was measured as the initial slope of the fEPSP in normal aCSF (Fontaine et al., 2013; Morrison et al., 2013). The ratio of AMPAR to NMDAR was measured as the slope of fEPSP recorded in normal aCSF to that recorded in NBQX and low $\mathrm{Mg}^{2+}$ at the same stimulation intensity. Ifenprodil ( $3 \mu \mathrm{M}$, an NR2B antagonist; Tocris Bioscience) was used to isolate the non-NR2B NMDAR synaptic potential and bath applied to the slice for $30 \mathrm{~min}$. The NR2B mediated fEPSP was measured as the fraction of NMDAR fEPSP that was blocked by ifenprodil.

For LTP recording, a baseline of fEPSPs evoked by single pulse test stimulation was recorded at $0.05 \mathrm{~Hz}$ until the last $10 \mathrm{~min}$ were consistent and was then followed by eight $\theta$ burst stimulations ( 10 times $5 \mathrm{~Hz}$ trains, each train contains 5 pulses at $100 \mathrm{~Hz}$ ) separated by 30 s. The stimulation intensity for recording and stimulation was determined as that at which $50 \%$ of the maximum response was evoked. For LTD recording, the same procedure was used, except the induction was initiated by 900 lowfrequency stimulations at $1 \mathrm{~Hz}$. The stimulation intensity was set to

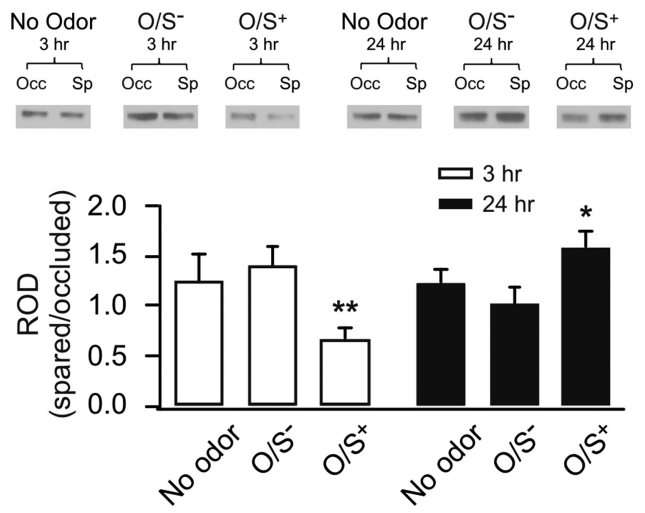

Figure 1. NMDA NR1 plasticity in the aPC at 3 and $24 \mathrm{~h}$ after early odor preference learning. Western blots of synaptoneurosome extracts of aPCs from occluded and spared hemispheres of the same animals. Top, Example Western blot bands of NR1 in different groups. Occ, Occluded; $\mathrm{Sp}$, spared. Bottom, relative optical density (ROD) of NR1 expressions in various groups. The values are normalized NR1 expressions in spared aPCs to the occluded counterparts. ${ }^{*} p<0.05$. ${ }^{* *} p<0.01$. Error bars indicate mean \pm SEM.

provoke $60-70 \%$ of the maximal fEPSP response. In a subset of LTD experiments, MK-801 (40 $\mu \mathrm{M})$ was bath applied to the slice for $10 \mathrm{~min}$ before induction and washed out after induction. The recordings were analyzed to determine the amount of LTP or LTD (compared with the baseline) at the LOT to aPC synapses. Data were binned to demonstrate the fEPSP value per minute.

\section{Results}

\section{Plasticity of NMDARs in the aPC 3 and $24 \mathrm{~h}$ after early odor preference learning}

Morrison et al. (2013) showed that early odor preference training results in increased AMPAR responses at the LOT synapses in the aPC at both 3 and $24 \mathrm{~h}$ after training. NMDARs in the aPC mediate early odor preference learning and likely mediate the AMPAR LTP observed ex vivo after learning. The present study tests whether the NMDAR itself undergoes plasticity after early odor preference learning.

Rat pups underwent early odor preference learning with single naris occluded during training. Western blot analyses of synaptoneurosome extracts from the aPC of occluded and spared hemispheres were compared at 3 or $24 \mathrm{~h}$ time points after training. A one-way ANOVA revealed significant differences among groups $\left(F_{(5,41)}=3.17, p<0.05\right.$; Fig. 1$)$. At $3 \mathrm{~h}$ after $\mathrm{O} / \mathrm{S}^{+}$learning, there was a significant downregulation in NR1 $(0.67 \pm 0.12$, $n=9)$ that was not found $3 \mathrm{~h}$ after $\mathrm{O} / \mathrm{S}^{-}$training $(1.40 \pm 0.19$, $n=9)$. At $24 \mathrm{~h}$, there was a significant upregulation in NR1 in $\mathrm{O} / \mathrm{S}^{+}(1.59 \pm 0.15, n=7)$ animals, and not $\mathrm{O} / \mathrm{S}^{-}$animals $(1.02 \pm 0.18, n=8)$. Animals that did not receive any training and were subjected to naris occlusions only did not show different NR1 levels from two hemispheres at either time point. Post hoc Fisher LSD tests showed that $\mathrm{O} / \mathrm{S}^{+} 3 \mathrm{~h}$ pups expressed significantly less NR1 compared with both no odor $3 \mathrm{~h}$ animals $(p<$ $0.05)$ and $\mathrm{O} / \mathrm{S}^{-} 3 \mathrm{~h}$ animals $(p<0.01) . \mathrm{O} / \mathrm{S}^{+} 24 \mathrm{~h}$ animals yielded significantly higher NR1 expression compared to $\mathrm{O} / \mathrm{S}^{-}$ $24 \mathrm{~h}$ animals $(p<0.05)$. Together, these results suggest that conditioning leads to NMDAR NR1 subunit expression downregulation $3 \mathrm{~h}$ and an upregulation $24 \mathrm{~h}$ after $\mathrm{O} / \mathrm{S}^{+}$training.

Next, we examined the expression of NMDAR plasticity in the aPC. We focused on the LOT afferent input synapses where AMPAR LTP was previously observed after early odor preference learning (Fontaine et al., 2013; Morrison et al., 2013). Ex vivo electrophysiology was conducted 3 or $24 \mathrm{~h}$ after lateralized odor training $\left(\mathrm{O} / \mathrm{S}^{+}\right)$. Lateralized training allows a within- 


\section{$3 \mathrm{hr}$ post-O/S+}

A1

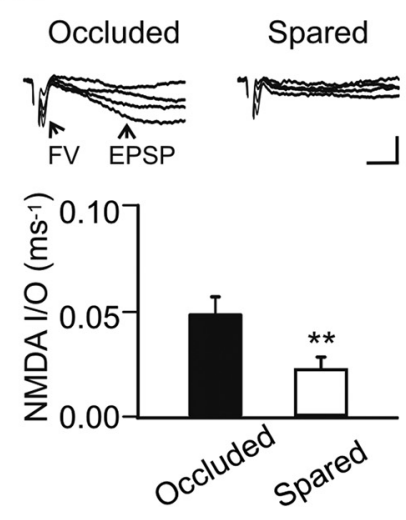

B1
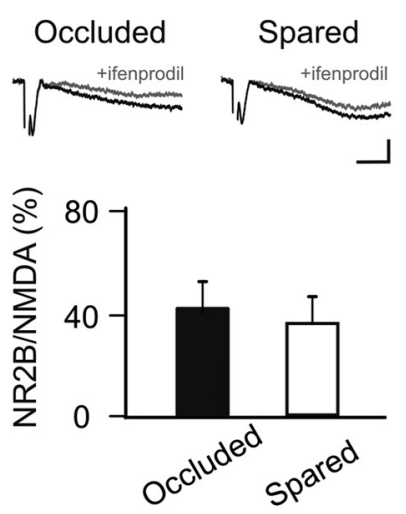

$24 \mathrm{hr}$ post-O/S

A2

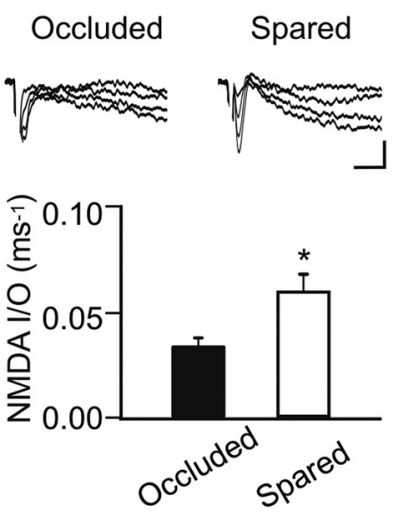

B2
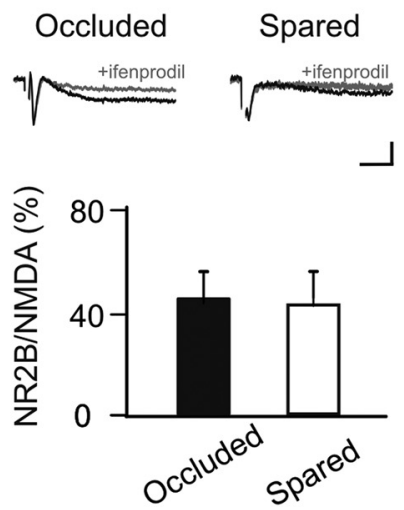

C1
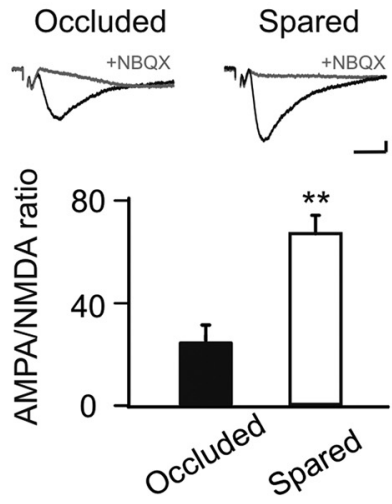

C2
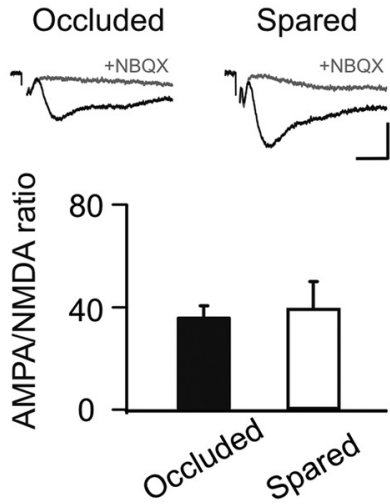

Figure 2. NMDAR downregulation at $3 \mathrm{~h}$ and upregulation at $24 \mathrm{~h}$ occur at the $\mathrm{L} 0 \mathrm{~T}$ synapse. $\boldsymbol{A 1}, \boldsymbol{A 2}$, NMDAR I/0 relationship recorded at $3 \mathrm{~h}(\boldsymbol{A} \mathbf{1})$ and $24 \mathrm{~h}(\boldsymbol{A} \mathbf{2})$ ex vivo after early odor preference

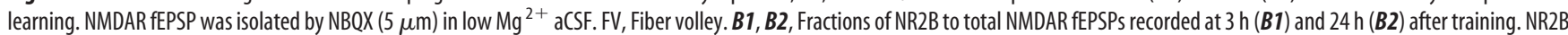
component was isolated by ifenprodil $(3 \mu \mathrm{m})$, an NR2B antagonist. C1, C2, AMPAR/NMDAR ratio recorded at $3 \mathrm{~h}(C 1)$ and $24 \mathrm{~h}(C 2)$ after training. Calibration: $0.2 \mathrm{mV}, 5 \mathrm{~ms} .{ }^{*} p<0.05 .{ }^{* *} p<0.01$. Error bars indicate mean \pm SEM.

animal control at this age (Yuan and Harley, 2012; Fontaine et al., 2013; Morrison et al., 2013). We measured the NMDAR fEPSP I/O relationship in the presence of NBQX. The I/O relationship measuring the ratio of fEPSP slope to the presynaptic fiber volley of the LOT allows us to directly compare the relative number of functional NMDARs at LOT synapses from spared and occluded hemispheres of the same animals (Franks and Isaacson, 2005; Yuan and Harley, 2012). A paired $t$ test showed that, at $3 \mathrm{~h}$ after training, there was a decrease in the NMDAR I/O in the spared $(0.021 \pm 0.004, n=6)$ hemisphere compared with the occluded hemisphere (0.049 $\pm 0.007 ; n=6, t=5.75, p<0.01$; Fig. 2A1), indicating less NMDAR response for a given input. However, at $24 \mathrm{~h}$ after $\mathrm{O} / \mathrm{S}^{+}$training, there was an increase in NMDAR I/O in the spared $(0.060 \pm 0.008, n=7)$ versus the occluded hemisphere (0.034 $\pm 0.004, n=7, t=2.71, p<0.05$; Fig. 2A2).

The decrease of NMDAR fEPSPs at $3 \mathrm{~h}$ and the increase at $24 \mathrm{~h}$ after odor training are consistent with the changes of NR1 subunit expression levels observed with Western blotting, suggesting plasticity of NR1 occurs at the LOT synapses. To test whether there is also an NMDAR composition change, such as a switch from NR2B to NR2A subunits, as observed after odor associative learning in adult rats (Quinlan et al., 2004), we measured the percentage of the NR2B response relative to the total NMDAR
fEPSP. At both $3 \mathrm{~h}(42.4 \pm 10.27 \%$ occluded vs $37.24 \pm 8.99$ spared, $n=5, t=0.29, p>0.05$; Fig. 2B1), and $24 \mathrm{~h}(45.92 \pm$ 9.61\% occluded vs $43.48 \pm 12.20$ spared, $n=7, t=0.19, p>$ 0.05; Fig. 2B2), there was no difference in the fraction of NR2B responses. Together, these results suggest NMDAR plasticity at the LOT synapse after early odor preference learning, is the result of changes in the numbers of NR1 essential subunits. The fractions of NR2B subunits are similar in both hemispheres suggesting that NR2B levels parallel NR1 levels and there are no subunit composition changes.

NR1 downregulation at $3 \mathrm{~h}$ coincides with decreased LTP and increased LTD at the LOT synapse

What is the consequence of the changes in NMDARs for the synaptic state and plasticity? We first looked at the ratio of AMPAR to NMDAR response at the LOT synapse after learning. We found that there was an increase in the AMPAR/ NMDAR ratio at $3 \mathrm{~h}(28.17 \pm 3.47$ occluded vs $66.56 \pm 6.47$ spared, $n=6, t=4.46, p<0.01$; Fig. $2 C 1)$. This is consistent with both an increase in AMPAR response as observed previously (Morrison et al., 2013) and a decrease in the NMDAR response as observed in this study. However, at $24 \mathrm{~h}$ after training, there was no difference between the occluded hemisphere $(37.15 \pm 4.03$, 
A

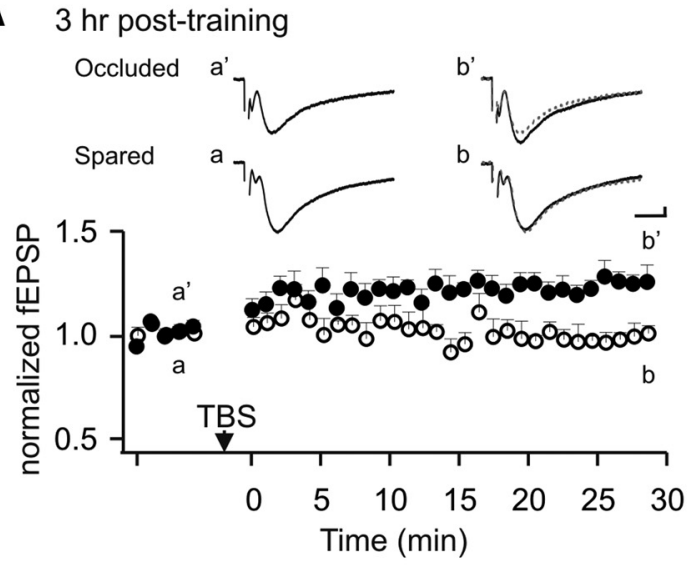

C 24 hr post-training

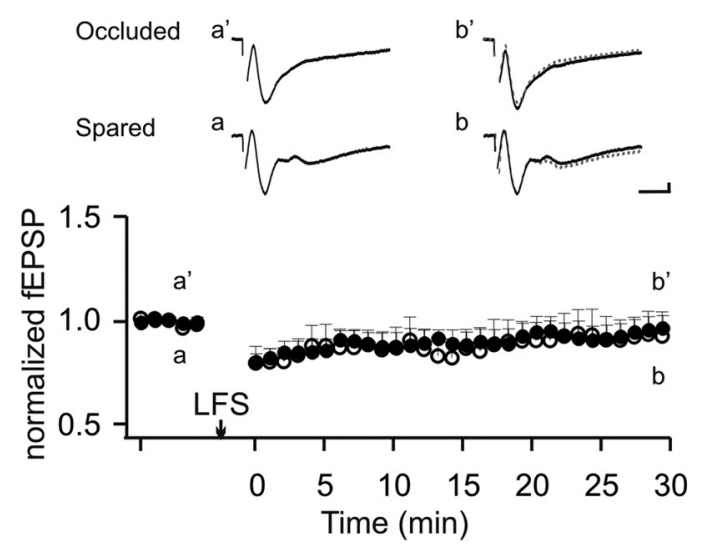

B $3 \mathrm{hr}$ post-training

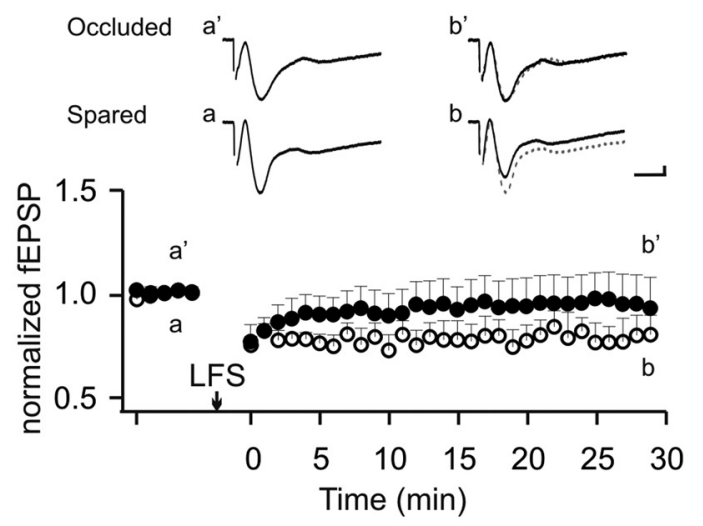

Figure 3. NMDAR downregulation at $3 \mathrm{~h}$ coincides with decreased LTP and inducibility of LTD at the LOT synapse. $A$, Ex vivo LTP induction $3 \mathrm{~h}$ after training in occluded and spared aPCs from the same animals. TBS, $\theta$ burst stimulation. $\boldsymbol{B}$, Ex vivo LTD induction $3 \mathrm{~h}$ after training. LFS, Low-frequency stimulation. $\boldsymbol{C}$, Ex vivo LTD induction $24 \mathrm{~h}$ after training. Solid circles represent data from occluded aPC. Open circles represent data from spared aPC. Calibration: $0.2 \mathrm{mV}, 5 \mathrm{~ms}$. Error bars indicate mean \pm SEM.

$n=7)$ and the spared hemisphere (40.45 $\pm 9.62, n=7, t=0.36$, $p>0.05$; Fig. 2C2). The finding of no change in the AMPAR/ NMDAR ratio at $24 \mathrm{~h}$ is likely the result of proportional increases in both AMPAR (Morrison et al., 2013) and NMDAR responses. Developmentally, an increased AMPAR/NMDAR ratio coincides with decreased AMPAR LTP in the olfactory cortex (Franks and Isaacson, 2005).

We then explored how changes in NMDAR expression and response after early odor learning shape synaptic plasticity at the LOT synapse. It has been shown that LTP at the LOT synapse is excluded in the trained hemisphere at $24 \mathrm{~h}$ after early odor preference learning (Morrison et al., 2013). Consistent with this result, we observed a learning-induced LTP exclusion effect also at $3 \mathrm{~h}$ after training. In the untrained hemispheres, on average the fEPSP slope size increased to $115.5 \pm 2.9 \%$ at 30 min after $\theta$ burst stimulation induction $(n=6)$, whereas in the trained hemisphere, no LTP of the fEPSP was observed $(95.9 \pm 4.2 \%, n=6)$. Accordingly, there was a significant difference between the two groups at $30 \mathrm{~min}$ after induction $(t=3.80, p<0.01$; Fig. $3 A)$. We next tested LTD inductions $3 \mathrm{~h}$ after odor training ex vivo in naris occluded versus spared hemispheres. A low-frequency induction protocol (900 pulses at $1 \mathrm{~Hz}$ ) (Lebel et al., 2001) resulted in LTD of the fEPSP in the spared hemisphere $(80.5 \pm 9.4 \%$ of the baseline, $n=6, t=2.08, p<0.05)$, but not in the occluded hemisphere $(105.7 \pm 18.3 \%$ of the baseline, $n=6, t=0.31, p>0.05$; Fig. $3 B$ ). Interestingly, at $24 \mathrm{~h}$ after odor training, there was no LTD induction and no difference in the two hemisphere groups
(96.8 $\pm 6.4 \%$ occluded vs $93.0 \pm 11.9 \%$ spared, $n=7, t=0.29$, $p>0.05$; Fig. $3 C$ ). Together with the previous report (Morrison et al., 2013), we show that, at $3 \mathrm{~h}$ after training, there is decreased LTP induction at the LOT synapse, in parallel with an increase in LTD induction. However, at $24 \mathrm{~h}$ after training, there is only decreased LTP induction, without a parallel and opposite change in LTD induction. Whereas an increased AMPAR response at both 3 and $24 \mathrm{~h}$ (Morrison et al., 2013) may result in a ceiling effect of synaptic LTP and account for LTP exclusion at both time points, a decrease in NMDARs at $3 \mathrm{~h}$ may also account for less LTP and appears to be solely responsible for a lower threshold for LTD induction. Downregulation of NMDAR induces metaplasticity that alters the plastic state of the previously active synapses.

\section{NR1 downregulation at $3 \mathrm{~h}$ interferes with learning at the same synapse}

What is the functional significance of NMDAR downregulation after early odor learning? Particularly, how would downregulation of NMDARs at $3 \mathrm{~h}$ after the first training influence another episode of learning at the same synapse? To answer this question, we designed experiments in which animals were trained in two trials separated by a $3 \mathrm{~h}$ interval. During the first training session, pups were assigned to one of the two bedding conditions and underwent $\mathrm{O} / \mathrm{S}^{+}$training: peppermint bedding or vanillin bedding. The vanillin bedding group was retrained with peppermint bedding $3 \mathrm{~h}$ later. Pups in the peppermint bedding group during the first training were divided into five groups: one group was 


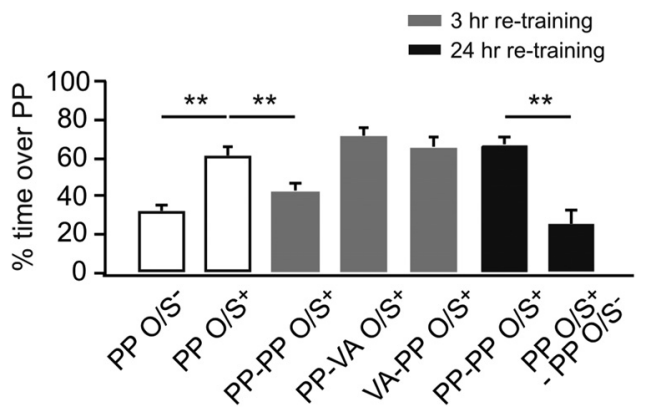

Figure 4. $0 / \mathrm{S}^{+}$retraining at $3 \mathrm{~h}$ impairs learning at the same synapse. Percentage of time spent over peppermint-scented bedding in a two choice test. PP, Peppermint; VA, vanillin; PP-PP, both first and retraining with peppermint-scented bedding; PP-VA, first training with peppermint-scented bedding, retraining with vanillin scented-bedding; VA-PP, first training with vanillin scented-bedding, retraining with peppermint scented-bedding. ${ }^{* *} p<0.01$. Error bars indicate mean $\pm S E M$.

retrained with peppermint bedding at $3 \mathrm{~h}$, one group was retrained with vanillin bedding at $3 \mathrm{~h}$, one group was retrained with peppermint bedding at $24 \mathrm{~h}$, one group was exposed to peppermint bedding only at $24 \mathrm{~h}$, and one group was not retrained. An $\mathrm{O} / \mathrm{S}^{-}$group trained once was also included as a negative control. Odor preference testing showed significant group effects $\left(F_{(6,56)}=14.70, p<0.01 ;\right.$ Fig. 4$)$. Interestingly, pups trained two times in peppermint bedding with a $3 \mathrm{~h}$ interval showed no preference learning for the peppermint $(42.98 \pm 3.88 \%, n=10) 24 \mathrm{~h}$ later, compared with the $\mathrm{O} / \mathrm{S}^{+}$one time training group $(61.30 \pm$ $4.78 \%, n=10, p<0.01)$. The vanillin bedding group showed normal $24 \mathrm{~h}$ learning to peppermint when retrained with peppermint bedding $3 \mathrm{~h}$ after the first training $(66.03 \pm 4.30 \%, n=10)$, compared with the $\mathrm{O} / \mathrm{S}^{-}$group $(31.92 \pm 3.62 \%, n=10, p<$ 0.01 ). Retraining with vanillin bedding did not impair the odor preference memory to the first training odor peppermint (71.69 $\pm 4.84 \%, n=7)$ compared with the $\mathrm{O} / \mathrm{S}^{-}$group $(p<$ $0.01)$. Pups trained two times in peppermint only bedding but separated by a $24 \mathrm{~h}$ interval did not show any learning deficiency $(66.77 \pm 4.41, n=9)$; this is in comparison with the group that was reexposed to peppermint only at $24 \mathrm{~h}$, which showed no preference memory to peppermint $(25.43 \pm 7.45 \%, n=7, p<$ 0.01 ). This suggests that any effect of retraining with peppermint + stroking cannot be explained by peppermint exposure itself and confirms the limited duration of one trial peppermint preference memory

Our results suggest that retraining at $3 \mathrm{~h}$ interferes with the expression of odor preference induced by initial exposure. This learning interference coincides with NMDAR downregulation, reduced LTP, and increased LTD induction at LOT synapses. To establish the causal relationship between NMDAR downregulation and learning deficiency, we infused siRNA that specifically downregulates the NMDA NR1 subunit into the aPCs. Western blots showed that $4 \mathrm{~d}$ after the initial injection of siRNA into the brain, the NR1 subunit was significantly downregulated compared with the control hemisphere, regardless of whether it was in the olfactory bulb $(51.4 \pm 12.3 \%$ of the control hemisphere, $n=$ $5, t=3.95, p<0.05$; Fig. $5 A)$ or in the aPC (33.7 $\pm 4.9 \%$ of the control counterpart, $n=6, t=13.62, p<0.01$; Fig. $5 B)$. Behavioral experiments $\left(F_{(3,30)}=3.66, p<0.05\right.$; Fig. $\left.5 C\right)$ demonstrated that siRNA bilateral infusion into the aPCs prevented early odor preference learning $(41.8 \pm 6.3 \%, n=10)$ compared with the controls $(67.0 \pm 6.1 \%, n=8, p<0.01)$. This result suggests that NR1 downregulation globally in the aPC results in odor learning

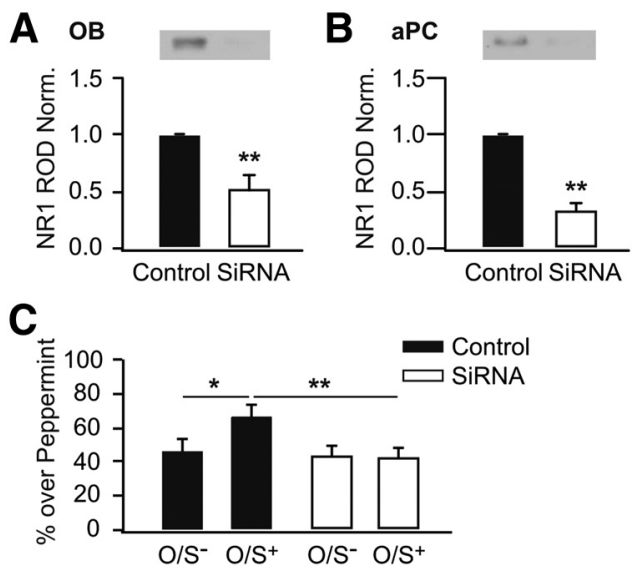

Figure 5. NR1 downregulation by siRNA impairs early odor preference learning. $\boldsymbol{A}$, Relative optical density (ROD) of NR1 in siRNA infused olfactory bulb (OB), normalized to non-targeting control counterpart. $\boldsymbol{B}, \mathrm{ROD}$ of NR1 in siRNA infused aPC, normalized to non-targeting control counterpart. $C$, Percentage of time spent over peppermint-scented bedding in a two choice test. ${ }^{*} p<0.05 .{ }^{* *} p<0.01$. Error bars indicate mean \pm SEM.

deficiency in rat pups. Therefore, it is likely that NR1 downregulation $3 \mathrm{~h}$ after the first training accounts for impaired learning during retraining.

\section{Metaplasticity at $3 \mathrm{~h}$ after early odor training is NMDAR-dependent}

How could retraining involving the same synapses that supported learning impair subsequent learning or memory expression? NMDAR downregulation at $3 \mathrm{~h}$ after the first training coincides with enhanced LTD induction at the LOT synapse. NMDAR-dependent $\mathrm{Ca}^{2+}$ influx is critical for both LTP and LTD. A high rise of intracellular $\mathrm{Ca}^{2+}$ through NMDAR triggers LTP and a slower, lower rise of $\mathrm{Ca}^{2+}$ favors LTD induction (Malenka and Bear, 2004; Luscher and Malenka, 2012). We tested the hypothesis that fewer NMDARs at the same synapse during retraining lower the amount of $\mathrm{Ca}^{2+}$ influx and favor LTD induction. We first asked, by using ex vivo slices $3 \mathrm{~h}$ after $\mathrm{O} / \mathrm{S}^{+}$ training, whether LTD induction at the LOT synapse is affected by NMDAR blockage. When MK-801, an NMDA open channel blocker, was bath applied to the slices, LTD induction was abolished (104.7 $\pm 10.9 \%$ of the baseline at $30 \mathrm{~min}$ after induction, $n=7, t=0.43, p>0.05$; Fig. 6). This result suggests that the NMDAR, and likely calcium influx through NMDAR, mediates LTD induction $3 \mathrm{~h}$ after $\mathrm{O} / \mathrm{S}^{+}$training.

We next examined whether NMDAR blockage during retraining would allow early odor preference memory to be expressed. We compared three groups: $3 \mathrm{~h}$ retraining with saline injection, $3 \mathrm{~h}$ retraining with a prior MK-801 injection, and an MK-801 injection only at $3 \mathrm{~h}$ without retraining. One-way ANOVA shows significant group effects $\left(F_{(2,27)}=16.67, p<0.01\right.$; Fig. 7$)$. Retraining at $3 \mathrm{~h}$ with a saline injection prevented the expression of odor preference memory tested at $24 \mathrm{~h}(29.38 \pm 4.32 \%, n=10)$, consistent with the previous result (Fig. 4). However, when MK801 was administered to the pups at the time of the $3 \mathrm{~h}$ retraining session, the odor preference memory at $24 \mathrm{~h}$ was intact (71.39 \pm $3.51 \%, n=10, p<0.01$ compared with the saline retraining group). MK-801 injection itself $3 \mathrm{~h}$ after the $\mathrm{O} / \mathrm{S}^{+}$training did not interfere with the expression of the odor preference memory (58.28 $\pm 7.22 \%, n=10, p<0.01$ compared with the saline retraining group). Together, these results suggest NMDAR blockage abolishes metaplasticity occurring at $3 \mathrm{~h}$ after the first 


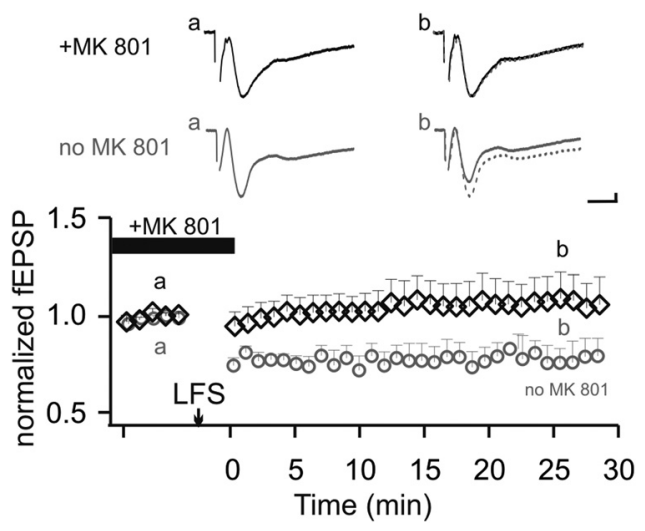

Figure 6. Ex vivo NMDAR blockage $3 \mathrm{~h}$ after odor training blocks LTD at the LOT synapse. Ex vivo LTD induction $3 \mathrm{~h}$ after $0 / \mathrm{S}^{+}$training in the presence of NMDAR antagonist MK-801. LFS, Low-frequency stimulation. Squares represent data from MK-801 experiments. Gray circles are taken from Figure $3 B$, recording in spared slices after $0 / \mathrm{S}^{+}$training without MK-801. Calibration: $0.2 \mathrm{mV}, 5 \mathrm{~ms}$. Error bars indicate mean $\pm \mathrm{SEM}$.

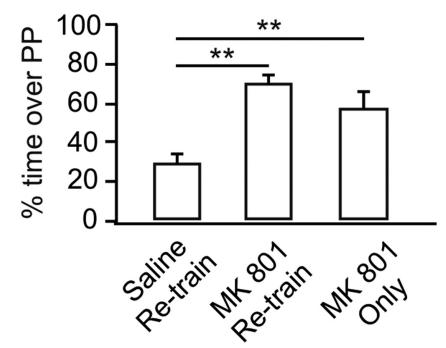

Figure 7. NMDAR blockage during retraining allows odor preference memory to be expressed. Percentage of time spent over peppermint (PP)-scented bedding in a two choice test. Saline or MK- 801 was injected to pups before $3 \mathrm{~h}$ retraining. MK- 801 only group refers to MK-801 injection at $3 \mathrm{~h}$ without retraining. ${ }^{* *} p<0.01$. Error bars indicate mean \pm SEM.

Table 1. Summary of synaptic plasticity and metaplasticity in the aPC after early odor preference learning

\begin{tabular}{lcc}
\hline & $3 \mathrm{~h}$ & $24 \mathrm{~h}$ \\
\hline AMPA I/0 & $\uparrow^{a}$ & $\uparrow^{a}$ \\
NMDA I/0 & $\downarrow$ & $\uparrow$ \\
NR1 & $\downarrow$ & - \\
$\%$ NR2B & - & - \\
AMPA/NMDA & $\uparrow$ & $\downarrow^{a}$ \\
LTP induction & $\downarrow$ & - \\
LTD induction & $\uparrow$ & Odor memory intact \\
Retraining @ & No odor memory & No \\
Metaplasticity & NMDAR-dependent & \\
\hline
\end{tabular}

${ }^{a}$ Results from Morrison et al. (2013).

$\mathrm{O} / \mathrm{S}^{+}$training but does not affect the expression of already formed memory from the first $\mathrm{O} / \mathrm{S}^{+}$training.

The key results in this study are summarized in Table 1.

\section{Discussion}

Biphasic NMDAR plasticity after early odor preference learning in rats

Here we report biphasic changes in NMDAR synaptic transmission and in absolute amount of the essential subunit NR1 in the aPC after early odor preference learning in rats. NMDAR LTD was inducible at the LOT to pyramidal cell synapse $3 \mathrm{~h}$ after odor training. Contrary to what was seen with odor rule learning in adult rats (Quinlan et al., 2004), in which a switch from the NR2B to NR2A subunit occurred after learning, we observed no change in the NR2B-mediated synaptic potential relative to the total NMDAR response in the learning hemisphere compared with control. This suggests downregulation of the NR1 subunit at the LOT synapse is responsible for the reduced NMDAR synaptic transmission $3 \mathrm{~h}$ after training.

Consistent with a previous report in nucleus accumbens (Kombian and Malenka, 1994), NMDAR LTD $3 \mathrm{~h}$ after odor training is concurrent with AMPAR LTP (Morrison et al., 2013). It is likely that both the AMPAR LTP and NMDAR LTD are mediated through $\mathrm{Ca}^{2+}$ influx through NMDARs (Bellone and Nicoll, 2007) and implies that the same postsynaptic $\mathrm{Ca}^{2+}$ concentration induces opposite effects on AMPAR- and NMDARmediated synaptic responses (Kombian and Malenka, 1994).

At $24 \mathrm{~h}$ after training, we observed LTP of the same NMDARmediated synaptic responses, likely because of NR1 upregulation at the LOT synapse. This delayed NMDAR LTP accompanies AMPAR LTP at the same synapse (Morrison et al., 2013), which restores the AMPAR to NMDAR ratio to control levels.

Despite extensive characterization of NMDAR plasticity in vitro (Abraham and Bear, 1996; Lee et al., 2010; Hunt and Castillo, 2012), activity-dependent changes of NMDARs after behavioral conditioning have been less commonly reported (Hunt and Castillo, 2012). Changes of NMDAR subunit composition, such as the switch between NR2B and NR2A subunits, underlie developmental changes (Carmignoto and Vicini, 1992), sensory deprivation/enrichment effects (Philpot et al., 2001), and associative learning (Quinlan et al., 2004). The differential activation of NMDAR subunits translates into different dynamics for NMDAR ion conductance and charge transfer, which influence NMDAR-mediated synaptic integration and plasticity (Bellone and Nicoll, 2007).

Induction mechanisms for the biphasic NMDAR changes after early odor preference learning require further investigation. In vitro work shows that, similar to AMPAR plasticity, both LTP and LTD of NMDAR require either NMDAR or mGluR activation, and a postsynaptic $\mathrm{Ca}^{2+}$ rise (Hunt and Castillo, 2012). Postsynaptic $\mathrm{Ca}^{2+}$ influx activates the enzymatic signaling required for plasticity, including protein kinases PKA (Harnett et al., 2009), PKC (Grosshans et al., 2002; Harney and Anwyl, 2012), and Src (Grosshans et al., 2002; Li et al., 2011) for LTP induction, and phosphatases, such as protein phosphatase 1 (PP1)/PP2A, for LTD induction (Morishita and Malenka, 2008).

Expression mechanisms involve NMDAR trafficking into, and out of, the synaptic membrane through endocytosis/exocytosis as well as lateral movement (Hunt and Castillo, 2012). NMDAR LTD can be mediated by $\mathrm{Ca}^{2+}$-dependent actin depolymerization, which promotes lateral diffusion of NMDARs from synaptic membrane to extrasynaptic sites (Morishita and Malenka, 2008; Peng et al., 2010), or dynamin-dependent endocytosis (Montgomery et al., 2005). LTP of the NMDAR can be expressed by exocytosis of NMDARs via SNARE-dependent processes (Kwon and Castillo, 2008) or recruitment of NMDARs from extrasynaptic sites to the synaptic membrane (Harney et al., 2008).

It is unclear how the biphasic changes in NMDARs, seen here after a single odor preference training session, occur. The initial depression may involve only transient receptor trafficking out of the synaptic membrane independent of new protein synthesis, or only local synaptic proteins and mRNA may be involved, whereas the later potentiation may result from homeostatic regulation to match AMPAR number (Watt et al., 2004) and require protein synthesis. If this were true, separate signaling would be involved 
in the early LTD and late LTP of NMDARs after early odor preference training.

\section{Downregulation of NMDAR leads to synaptic and behavioral metaplasticity}

Metaplasticity refers to the change of capacity for synaptic plasticity resulting from prior synaptic activity (Abraham and Bear, 1996). Given the role of NMDARs in mediating AMPAR synaptic plasticity, one consequence of NMDAR plasticity is a change in the ability to induce NMDAR-dependent plasticity of AMPARmediated synaptic transmission (Hunt and Castillo, 2012). Studies in visual cortex demonstrate changes in LTP or LTD capability after periods of altered visual experience (Kirkwood et al., 1996; Philpot et al., 2001). Our results provide direct evidence in support of NMDAR plasticity as a mechanism for metaplasticity in natural learning.

We show that downregulation of the NR1 subunit and LTD of NMDAR-mediated synaptic responses $3 \mathrm{~h}$ after odor preference learning coincides with decreased AMPAR LTP (depotentiation) and increased AMPAR LTD. This shift favoring LTD induction is not solely the result of synaptic ceiling effects on AMPARs because, at $24 \mathrm{~h}$, LTD of the AMPAR is no longer inducible, whereas LTP of the AMPAR persists (Morrison et al., 2013). Together, NR1 downregulation and NMDAR LTD are most likely to account for the threshold shifts for AMPAR LTP and LTD induction.

Behavioral metaplasticity has been used to refer to the ability of stress experiences to alter behavioral learning because of system-wide changes (Schmidt et al., 2013). Here, behavioral metaplasticity occurs at specific synapses. A shift in the threshold of AMPAR synaptic plasticity induced by training has consequences for learning using the same synapse. Three hours after initial training, retraining with the same odor + stroking protocol, not only did not consolidate initial learning, as is seen with repeated training at $24 \mathrm{~h}$, but impaired odor learning. Initial training induced LTD of NMDARs, leading to metaplasticity of AMPAR-mediated synaptic responses. Retraining at the same synapse likely caused depotentiation of AMPAR LTP or caused AMPAR LTD and, either way, abolished odor preference learning. The metaplasticity here is pathway-specific as training with two different odors with the same $3 \mathrm{~h}$ interval did not interfere with preference learning for peppermint odor. Input specificity of behavioral metaplasticity is consistent with in vitro work demonstrating synapse-specific metaplasticity in hippocampus (Izumi et al., 1992; O’Dell and Kandel, 1994; Fujii et al., 1996).

Metaplasticity at the LOT synapse after early odor preference learning not only results from changes in NMDAR number, but as seen in vitro (Izumi et al., 1992; O’Dell and Kandel, 1994; Fujii et al., 1996), depends on the NMDAR itself for its expression. NMDAR blockade abolished the AMPAR LTD induced $3 \mathrm{~h}$ after odor training. Furthermore, blocking NMDARs before retraining permitted odor preference memory expression. It requires further investigation to know how retraining at $3 \mathrm{~h}$ impairs odor preference memory. However, one likely explanation is that NMDAR downregulation at $3 \mathrm{~h}$ results in less $\mathrm{Ca}^{2+}$ influx through NMDARs during retraining and favors AMPAR LTD or AMPAR LTP depotentiation.

\section{Functional significance of NMDAR metaplasticity}

How metaplasticity occurs in vivo in a way that is relevant to cognitive function is not well understood (Hulme et al., 2013). Behavioral metaplasticity is proposed to alter learning and memory, and the likely mechanism is altered capacity for syn- aptic plasticity (Schmidt et al., 2013). Studies on stressinduced metaplasticity support this view. Behavioral stress impairs LTP induction and hippocampal-dependent learning and involves NMDAR activation (Kim and Diamond, 2002). Stress, or high levels of corticosterone, may also impair recollection of previously acquired memories.

Behavioral stress appears to retard plasticity at a global level involving multiple brain structures (Schmidt et al., 2013), but the present study provides some of the first evidence that learning itself affects future learning capacity at the same synapses. A recent study of amygdala-dependent fear conditioning showed that a weak training trial that does not produce fear memory primes future learning such that another trial delivered $60 \mathrm{~min}$ to $3 \mathrm{~d}$ later results in long-lasting and robust fear memory (Parsons and Davis, 2012). Together, these studies suggest that behavioral metaplasticity occurs, and the strength of the priming event may determine the nature and time course of the synaptic changes and the character of the behavioral modulation.

There are two ways to view the present results. Downregulation of the NMDAR is physiologically necessary after activation, and the behavioral effect is adventitious. Or downregulation supports a behaviorally relevant homeostatic regulation of learning. Substantial increases in circuit strength and consequent dominant sensory control over approach behavior may be limited, particularly in the case of sustained odors, by a waxing and waning mediated by the metaplasticity change described. Odor preference must be sufficiently weak to permit pups to leave the dam as they become more mobile. Consistent with such variation in odor preference learning is evidence that preference for peppermint constantly present in the maternal cage fades rapidly after exposure ends, whereas peppermint on the dam, providing a more variable stimulus over the same period, produces an enduring preference (Galef, 1982).

Correspondingly, multiple spaced presentations of odor + stroking at $24 \mathrm{~h}$ intervals produces an enduring preference compared with a single association, as might be predicted from the present NMDAR changes (Woo and Leon, 1987; Fontaine et al., 2013). Understanding behavioral metaplasticity, both globally and through pathway-specific changes, has significant implications for enhancing stimulus-specific adaptive learning and for diminishing, or ameliorating, the behavioral impact of traumatic learning.

\section{References}

Abraham WC, Bear MF (1996) Metaplasticity: the plasticity of synaptic plasticity. Trends Neurosci 19:126-130. CrossRef Medline

Bellone C, Nicoll RA (2007) Rapid bidirectional switching of synaptic NMDA receptors. Neuron 55:779-785. CrossRef Medline

Carmignoto G, Vicini S (1992) Activity-dependent decrease in NMDA receptor responses during development of the visual cortex. Science 258: 1007-1011. CrossRef Medline

Cummings DM, Henning HE, Brunjes PC (1997) Olfactory bulb recovery after early sensory deprivation. J Neurosci 17:7433-7440. Medline

Fontaine CJ, Harley CW, Yuan Q (2013) Lateralized odor preference training in rat pups reveals an enhanced network response in anterior piriform cortex to olfactory input that parallels extended memory. J Neurosci 33: 15126-15131. CrossRef Medline

Franks KM, Isaacson JS (2005) Synapse-specific downregulation of NMDA receptors by early experience: a critical period for plasticity of sensory input to olfactory cortex. Neuron 47:101-114. CrossRef Medline

Fujii S, Kuroda Y, Miura M, Furuse H, Sasaki H, Kaneko K, Ito K, Chen Z, Kato H (1996) The long-term suppressive effect of prior activation of synaptic inputs by low-frequency stimulation on induction of long-term potentiation in CA1 neurons of guinea pig hippocampal slices. Exp Brain Res 111:305-312. Medline

Galef BG Jr (1982) Acquisition and waning of exposure-induced attraction 
to a nonnatural odor in rat pups. Dev Psychobiol 15:479-490. CrossRef Medline

Gregory EH, PfaffDW (1971) Development of olfactory-guided behavior in infant rats. Physiol Behav 6:573-576. CrossRef Medline

Grimes MT, Smith M, Li X, Darby-King A, Harley CW, McLean JH (2011) Mammalian intermediate-term memory: new findings in neonate rat. Neurobiol Learn Mem 95:385-391. CrossRef Medline

Grosshans DR, Clayton DA, Coultrap SJ, Browning MD (2002) LTP leads to rapid surface expression of NMDA but not AMPA receptors in adult rat CA1. Nat Neurosci 5:27-33. CrossRef Medline

Harnett MT, Bernier BE, Ahn KC, Morikawa H (2009) Burst-timingdependent plasticity of NMDA receptor-mediated transmission in midbrain dopamine neurons. Neuron 62:826-838. CrossRef Medline

Harney SC, Anwyl R (2012) Plasticity of NMDA receptor-mediated excitatory postsynaptic currents at perforant path inputs to dendrite-targeting interneurons. J Physiol 590:3771-3786. CrossRef Medline

Harney SC, Jane DE, Anwyl R (2008) Extrasynaptic NR2D-containing NMDARs are recruited to the synapse during LTP of NMDAR-EPSCs. J Neurosci 28:11685-11694. CrossRef Medline

Hulme SR, Jones OD, Abraham WC (2013) Emerging roles of metaplasticity in behaviour and disease. Trends Neurosci 36:353-362. CrossRef Medline

Hunt DL, Castillo PE (2012) Synaptic plasticity of NMDA receptors: mechanisms and functional implications. Curr Opin Neurobiol 22:496-508. CrossRef Medline

Izumi Y, Clifford DB, Zorumski CF (1992) Inhibition of long-term potentiation by NMDA-mediated nitric oxide release. Science 257:1273-1276. CrossRef Medline

Kim JJ, Diamond DM (2002) The stressed hippocampus, synaptic plasticity and lost memories. Nat Rev Neurosci 3:453-462. CrossRef Medline

Kirkwood A, Rioult MC, Bear MF (1996) Experience-dependent modification of synaptic plasticity in visual cortex. Nature 381:526-528. CrossRef Medline

Kombian SB, Malenka RC (1994) Simultaneous LTP of non-NMDA- and LTD of NMDA-receptor-mediated responses in the nucleus accumbens. Nature 368:242-246. CrossRef Medline

Kucharski D, Hall WG (1987) New routes to early memories. Science 238: 786-788. CrossRef Medline

Kwon HB, Castillo PE (2008) Long-term potentiation selectively expressed by NMDA receptors at hippocampal mossy fiber synapses. Neuron 57 : 108-120. CrossRef Medline

Lebel D, Grossman Y, Barkai E (2001) Olfactory learning modifies predisposition for long-term potentiation and long-term depression induction in the rat piriform (olfactory) cortex. Cereb Cortex 11:485-489. CrossRef Medline

Lee MC, Yasuda R, Ehlers MD (2010) Metaplasticity at single glutamatergic synapses. Neuron 66:859-870. CrossRef Medline

Lethbridge R, Hou Q, Harley CW, Yuan Q (2012) Olfactory bulb glomerular NMDA receptors mediate olfactory nerve potentiation and odor preference learning in the neonate rat. PLoS One 7:e35024. CrossRef Medline

Li S, Cao J, Yang X, Suo ZW, Shi L, Liu YN, Yang HB, Hu XD (2011) NR2B phosphorylation at tyrosine 1472 in spinal dorsal horn contributed to $\mathrm{N}$-methyl-D-aspartate-induced pain hypersensitivity in mice. J Neurosci Res 89:1869-1876. CrossRef Medline

Luscher C, Malenka RC (2012) NMDA receptor-dependent long-term potentiation and long-term depression (LTP/LTD). Cold Spring Harb Perspect Biol 4:6. CrossRef Medline

Malenka RC, Bear MF (2004) LTP and LTD: an embarrassment of riches. Neuron 44:5-21. CrossRef Medline

McLean JH, Harley CW, Darby-King A, Yuan Q (1999) pCREB in the neo- nate rat olfactory bulb is selectively and transiently increased by odor preference-conditioned training. Learn Mem 6:608-618. CrossRef Medline

Montgomery JM, Selcher JC, Hanson JE, Madison DV (2005) Dynamindependent NMDAR endocytosis during LTD and its dependence on synaptic state. BMC Neurosci 6:48. CrossRef Medline

Morishita W, Malenka RC (2008) Mechanisms underlying dedepression of synaptic NMDA receptors in the hippocampus. J Neurophysiol 99:254263. CrossRef Medline

Morrison GL, Fontaine CJ, Harley CW, Yuan Q (2013) A role for the anterior piriform cortex in early odor preference learning: evidence for multiple olfactory learning structures in the rat pup. J Neurophysiol 110:141-152. CrossRef Medline

O'Dell TJ, Kandel ER (1994) Low-frequency stimulation erases LTP through an NMDA receptor-mediated activation of protein phosphatases. Learn Mem 1:129-139. CrossRef Medline

Parsons RG, Davis M (2012) A metaplasticity-like mechanism supports the selection of fear memories: role of protein kinase A in the amygdala. J Neurosci 32:7843-7851. CrossRef Medline

Peng Y, Zhao J, Gu QH, Chen RQ, Xu Z, Yan JZ, Wang SH, Liu SY, Chen Z, Lu W (2010) Distinct trafficking and expression mechanisms underlie LTP and LTD of NMDA receptor-mediated synaptic responses. Hippocampus 20:646-658. CrossRef Medline

Philpot BD, Sekhar AK, Shouval HZ, Bear MF (2001) Visual experience and deprivation bidirectionally modify the composition and function of NMDA receptors in visual cortex. Neuron 29:157-169. CrossRef Medline

Quinlan EM, Lebel D, Brosh I, Barkai E (2004) A molecular mechanism for stabilization of learning-induced synaptic modifications. Neuron 41:185192. CrossRef Medline

Schmidt MV, Abraham WC, Maroun M, Stork O, Richter-Levin G (2013) Stress-induced metaplasticity: from synapses to behavior. Neuroscience 250:112-120. CrossRef Medline

Sullivan RM, Leon M (1987) One-trial olfactory learning enhances olfactory bulb responses to an appetitive conditioned odor in 7-day-old rats. Brain Res 432:307-311. Medline

Sullivan RM, Toubas P (1998) Clinical usefulness of maternal odor in newborns: soothing and feeding preparatory responses. Biol Neonate 74:402408. Medline

Sullivan RM, Wilson DA (2003) Molecular biology of early olfactory memory. Learn Mem 10:1-4. CrossRef Medline

Varendi H, Porter RH, Winberg J (1996) Attractiveness of amniotic fluid odor: evidence of prenatal olfactory learning? Acta Paediatr 85:12231227. CrossRef Medline

Watt AJ, Sjöström PJ, Häusser M, Nelson SB, Turrigiano GG (2004) A proportional but slower NMDA potentiation follows AMPA potentiation in LTP. Nat Neurosci 7:518-524. CrossRef Medline

Wilson DA, Sullivan RM (1994) Neurobiology of associative learning in the neonate: early olfactory learning. Behav Neural Biol 61:1-18. CrossRef Medline

Woo CC, Leon M (1987) Sensitive period for neural and behavioral response development to learned odors. Brain Res 433:309-313. Medline

Yuan Q, Harley CW (2012) What a nostril knows: olfactory nerve-evoked AMPA responses increase while NMDA responses decrease at $24 \mathrm{~h}$ after training for lateralized odor preference memory in neonate rat. Learn Mem 19:50-53. CrossRef Medline

Yuan Q, Harley CW, McLean JH (2003) Mitral cell betal and 5-HT2A receptor colocalization and cAMP coregulation: a new model of norepinephrine-induced learning in the olfactory bulb. Learn Mem 10:515. CrossRef Medline 